УДК 378.147

DOI:

Світлана Яцюк, кандидат педагогічних наук, доцент кафедри загальної математики та методики навчання інформатики Волинського національного університету імені Лесі Украӥнки Марія Хомяк, кандидат фізико-математичних наук, доиент кафедри загальної математики та методики навчання інформатики Волинського національного університету імені Лесі Украӥнки

Валентина Юнчик, старший викладач кафедри загальної математики та методики навчання інформатики Волинського національного університету імені Лесі Українки

Тетяна Чепрасова, кандидат педагогічних наук, дочент кафедри загальної математики та методики навчання інформатики Волинського національного університету імені Лесі Українки

\title{
ОСОБЛИВОСТІ НАВЧАННЯ ВЕБ-ТЕХНОЛОГІЙ РОЗРОБКИ НАВЧАЛЬНИХ СИСТЕМ МАЙБУТНІХ ВЧИТЕЛІВ ІНФОРМАТИКИ ТА МЕТОДИКА СТВОРЕННЯ НА ЇХ ОСНОВІ ВЛАСНИХ ОСВІТНІХ РЕСУРСІВ
}

У статті розглянуто та теоретично обтрунтовано використання сучасних веб-технологій розробки навчальних систем, таких як Bootstrap, YII2, Java Script, HTML5 ma CSS3. Розроблено методику створення власної веб-орієнтованої навчальної системи. Проведено аналіз теоретичних праць вітчизняних та зарубіжних фахівиів, який свідчить, що у контексті дослідження якості освіти не існує однозначної методики розробки веб-орієнтованих навчальних систем. Проте можна відзначити, що технології створення wеb-сайтів навчального призначення уже стають важливими складовими єдиного освітнього простору.

Ключові слова: система освіти; інформачійні технології; вчитель інформатики; веб-технології; освітній ресурс; навчальна система.

Puc. 1. Лim.10.

Svitlana Yatsiuk, Ph.D.(Pedagogy), Associate Professor of the General Mathematics and Methods of Teaching Computer Science Department Volyn Lesya Ukrayinka National University

Maria Khomyak, Ph.D.(Physical and Mathematical), Associate Professor of the General Mathematics and Methods of Teaching Computer Science Department Volyn Lesya Ukrayinka National University Valentyna Yunchik, Senior Lecturer of the General Mathematics and Methods of Teaching Computer Science Department Volyn Lesya Ukrayinka National University

Tatiana Cheprasova, Ph.D.(Pedagogy), Associate Professor of the General Mathematics and Methods of Teaching Computer Science Department Volyn Lesya Ukrayinka National University

\section{FEATURES OF TEACHING WEB-TECHNOLOGIES DEVELOPMENT OF EDUCATIONAL SYSTEMS FOR FUTURE TEACHERS OF INFORMATICS AND METHODS OF CREATION ON THE BASIS OF OWN EDUCATIONAL RESOURCES}

The article considers and theoretically substantiates the use of modern web technologies for training systems development, such as Bootstrap, YII2, Java Script, HTML5 and CSS3, as well as features and benefits of selected technologies: ASP, ASP.NET (Active Server Pages); JSP technologies (Java Server Pages); Sun called JSF (Java Server Faces); Common Gateway Interface (CGI); PHP (Personal Home Pages) technology. A method of creating your own web-based educational system has been developed. The analysis of theoretical works of domestic and foreign specialists is carried out, which shows that in the context of research of quality of education there is no unambiguous technique of development of web-oriented educational systems. However, it can be noted that the technology of creating web-sites for educational purposes is already becoming an important component of a single educational space. The method of creating an educational system on the example of the course "Workshop on school computer science course", which includes separate modules are divided into levels, namely: 1-2 classes, 3-4 classes, 5-6 classes, 7-9 classes and 10-11 classes. Emphasis is placed on the understanding of the future teacher

(C) С. Яцюк, М. Хомяк, В. Юнчик,

Т. Чепрасова, 2021 


\section{ОСОБЛИВОСТІ НАВЧАННЯ ВЕБ-ТЕХНОЛОГІЙ РОЗРОБКИНАВЧАЛЬНИХСИСТЕМ МАЙБУТНІХ ВЧИТЕЛІВ ІНФОРМАТИКИ ТА МЕТОДИКАСТВОРЕННЯ НАЇХОСНОВІ ВЛАСНИХ ОСВІТНІХРЕСУРСІВ}

the peculiarities of the methods of teaching computer science in each class and the implementation of the appropriate selection of tasks for each level. The developed Web model of the educational system consists of a number of modules authorizations; news; to work with students; methodical materials and recommendations (free access of registered users to all materials and recommendations, which are considered in the current lesson, assessment logs); mailing module. The Laravel framework is used, which specifies the name of the table to which the model belongs. When establishing external table relationships (foreign keys), we recommend prescribing them in models. They will allow you to easily query related models that match other tables and retrieve all the necessary data. At the next stage, the Restful API was developed, which will ensure the interaction of system components on a larger scale.

Keywords: a system of education; information technologies; computer science teacher; web technologies, educational resource; educational system.

$\Pi$ остановка проблеми. Система освіти на сучасному етапі неможлива без створення єдиного інформаційного простору. У законі України щодо національної програми інформатизації йде мова про інформатизацію кожної структурної ланки держави. Це стосується, зокрема, і системи освіти. А саме, повинні постійно вдосконалюватись і оновлюватись освітні програми, при проєктуванні яких необхідно враховувати сучасні форми, зміст навчання 3 впровадженням комп'ютерноорієнтованих методичних систем навчання. Наразі гостро стоїть питання щодо здатності випускників закладів вищої освіти самостійно вивчати, розробляти, впроваджувати в освітню діяльність інформаційні продукти та методику їх використання [1]. Розвиток інформаційних технологій стрімко рухається вгору, кількість програмних продуктів постійно зростає. І щоб підготувати молоде покоління до життя в інформатизованому суспільстві, заклади вищої освіти повинні підготувати професіоналів своєї справи, якими є і будуть вчителі інформатики.

Сучасний вчитель інформатики повинен самостійно приймати рішення щодо розв'язання тієї чи тієї педагогічної ситуації, використовуючи при цьому набуті знання з сучасних інформаційних технологій та засобами доступу до інформаційних ресурсів. Важливо, щоб майбутні вчителі інформатики володіли умінням самостійно створювати інформаційні ресурси, а також технологіï створення web-сайтів навчального призначення, які стають важливими складовими єдиного освітнього простору $[1 ; 2]$.

Аналіз останніх публікацій. Питання підготовки майбутніх вчителів інформатики досліджували такі науковці, як В. Биков, А. Верлань, О. Гончарова, Ю. Горошкао, А. Єршов, М. Жалдак, В. Клочко, Е. Кузнєцов, О. Кузнєцов, Ю. Машбиця, В. Монахов, Н. Морзе, С. Раков, Ю. Рамський, І. Роберт, 3. Сейдаметова, С. Семеріков, С. СмірноваТрибульська, О. Спірін, Ю. Триус та ін. Психологопедагогічні аспекти використання сучасних інформаційних ресурсів в навчальному процесі висвітлено в роботах В. Ледньова, О. Леонтьєва,
Ю.Машбицц, В.Паламарчук, І.Роберт,В.Розумовського, Н. Тализіноїтаінших

Однак у цих дослідженнях недостатньо розкрита проблема Веб-технологій розробки навчальних систем та методика створення на їх основі власних освітніх ресурсів. На цю соціальнозначущу проблему спрямоване пропоноване дослідження.

Метою дослідження $\epsilon$ теоретичне обгрунтування і особливості навчання Веб-технологій розробки навчальних систем майбутніх вчителів інформатики та розробка методики створення веб-орієнтованої навчальної системи.

Виклад основного матеріалу. Для розробки навчальних систем вважаємо доцільним використання мови розмітки HTML, PHP, каскадних таблиць стилів CSS, фреймворку Bootstrap та мови програмування JavaScript [3; 4 ; 5]. Ці технології легкі у використанні та не мають аналогів, за винятком фреймворку Bootstrap, який $\epsilon$ простим і зручним у користуванні. Для розробки використовуємо мову програмування РНР. Вона має повноцінну документацію і популярна серед веб-програмістів завдяки продуманій структурі [2; $7 ; 8 ; 10]$. Як базу даних будемо використовуємо MySQL[2].

У дослідженні ми розглянули основні особливості та переваги обраних технологій. А саме:

- ASP, ASP.NET (Active Server Pages) [2]. При використанні цієї технології, розробленої Microsoft, веб-майстер самостійно формує динамічно поновлювальні веб-сторінки.

- Технологія JSP (Java Server Pages) використовується для створення серверних сторінок Јava.

- Sun за назвою JSF (Java Server Faces) реалізуе технологію серверних сторінок Java.

- Common Gateway Interface (CGI) - технологія створення веб-додатків, які виконуються сервером.

- Технологія PHP (Personal Home Pages) [7; 10]. Інтерпретує впроваджений у HTML-сторінку код на скриптовій мові.

РНР надає програмісту інструмент для швидкого й ефективного розв'язання поставлених 


\section{ОСОБЛИВОСТІНАВЧАННЯ ВЕБ-ТЕХНОЛОГІЙ РОЗРОБКИНАВЧАЛЬНИХ СИСТЕМ МАЙБУТНІХ ВЧИТЕЛІВ ІНФОРМАТИКИ ТА МЕТОДИКА СТВОРЕННЯ НА ЇХ ОСНОВІ ВЛАСНИХ ОСВІТНІХ РЕСУРСІВ}

завдань. Вона є простою у використанні і гнучкою до потреб розробника. Технологію РНР використовують у поєднанні з HTML-кодом та JavaScript та іншими мовами Інтернетпрограмування [10]. Підтверджуємо високу продуктивність, відкритість коду, багатоплатформенність, наявністьпрограмних бібліотек технології РНР. Для створення веб-додатків рекомендуємо використовувати РНР фреймворки, які $\epsilon$ їх основою. Використання цих систем, дає змогу економити велику кількість часу, зменшити навантаження на процес розробки навчальних систем, позбавляючи від проблеми повторюваного коду, і швидко створювати якісні проєкти. 3 проведеного нами аналізу, для створення веб-орієнтованих навчальних систем рекомендуємо використовувати такі фреймворки, як Bootstrap та Yii [6]. Означені системи не потребують додаткового налаштування, мають вбудовану можливість підтримки багатомовності, зручні у використанні та надають високий рівень захищеності навчальних продуктів, розроблених на їх базі. При розробці навчальних систем рекомендуємо також використовувати мову розмітки гіпертекстових документів HTML5 та каскадну таблицю стилів CSS3, які є найкращими у побудові web-сторінки навчального призначення [2; 3; 4]. Для інтерактивної та активної взаємодії користувача 3 web-додатком (навчальною системою) використовується мова програмування java script. Java script - це динамічна, об'єктноорієнтована мова програмування [3; 5$]$.

Отже, дослідження показує, що для створення навчальних систем, найкраще користуватися такими веб-технологіями, як Bootstrap,YII2, Java Script, HTML5 та CSS3. Майбутні вчителі інформатики повинні уміти розробляти власну навчальну систему. Розглянемо методику створення такої системи на прикладі курсу “Практикум зі шкільного курсу інформатики".

Модель навчальної системи включає окремі модулі, які поділені за рівнями, а саме: 1-2 класи, 3-4 класи, 5-6 класи, 7-9 класи та 10-11 класи. Майбутній учитель має чітко розуміти особливості методики викладання інформатики у кожному класі і здійснити відповідний підбір задач для кожного рівня. Кожен такий модуль матиме таку структуру (рис. 1.).

Правильність виконання кожного завдання можна перевірити за допомогою кнопки ПЕРЕВІРИТИ і оцінити рівень своїх знань 3 тієї чи тієї теми. Після закінчення вивчення теми учням пропонується виконати спільний проєкт. Веб-модель навчальної системи повинна містить авторизацію та реєстрацію учнів. Це забезпечить додавання нових учнів у систему, відновлення поштової скриньки користувачів та їх авторизацію у системі, відновлення паролю, можливість створення даних в браузері для постійної авторизації користувача. Реєстрація учнів відбувається адміністратором системи. Учні не можуть самі зареєструватися в системі. Окрім авторизації, існують наступні модулі навчальної системи:

- новин;

- для роботи 3 учнями;

- методичних матеріалів та рекомендацій (вільний доступ зареєстрованих користувачів до усіх матеріалів та рекомендацій, які розглянуті на поточному уроці, журнали оцінок);

- розсилки.

Навчальна система містить базу даних таблиці, які відповідають за збереження тих чи тих даних. Рекомендуємо створити певну кількість моделей для роботи з кожною таблицею.

Використаємо фреймворк Laravel, який буде визначати назву таблиці, до якої належить модель за допомогою такої логіки - назва таблиці в базі даних є назвою моделі в однині [8]. При встановленні зовнішніх зв'язків таблиці (зовнішні ключі) рекомендуємо прописувати їх в моделях. Вони допоможуть у зручний спосіб виконувати запити до пов'язаних моделей, які відповідають іншим таблицям та витягувати всі потрібні дані.

На наступному етапі було проведено розробку Restful API. 3 цією оболонкою компоненти систем взаємодіють в набагато більшому масштабі; використовуються всі інтерфейси загальні; частини можна впроваджувати незалежно одна від одної; є проміжні елементи, які знижують відсоток затримки і посилюють безпеку з'єднання. Ми розробили закриту систему, доступ до якої здійснюється через авторизацію в системі. Тому якщо користувач має недостатньо прав, система видає про це повідомлення.

У розробленій навчальній системі прослідковується чітка валідація даних, що дасть змогу уникати помилок через некоректність даних. Окрім того, система використовує методологію MVC, яка розподіляє дані, подання та обробку дій користувача на такі компоненти:

1. Модель / Model - надає собою об'єктну модель якоїсь предметної області, включає в себе дані і методи роботи з цими даними, реагує на запити 3 контролера, повертаючи дані і / або змінюючи свій стан. При цьому модель не містить в собі інформації про способи візуалізації даних або форматах їх подання, а також не взаємодіє 3 користувачем безпосередньо.

2. Подання / View - відповідає за відображення 

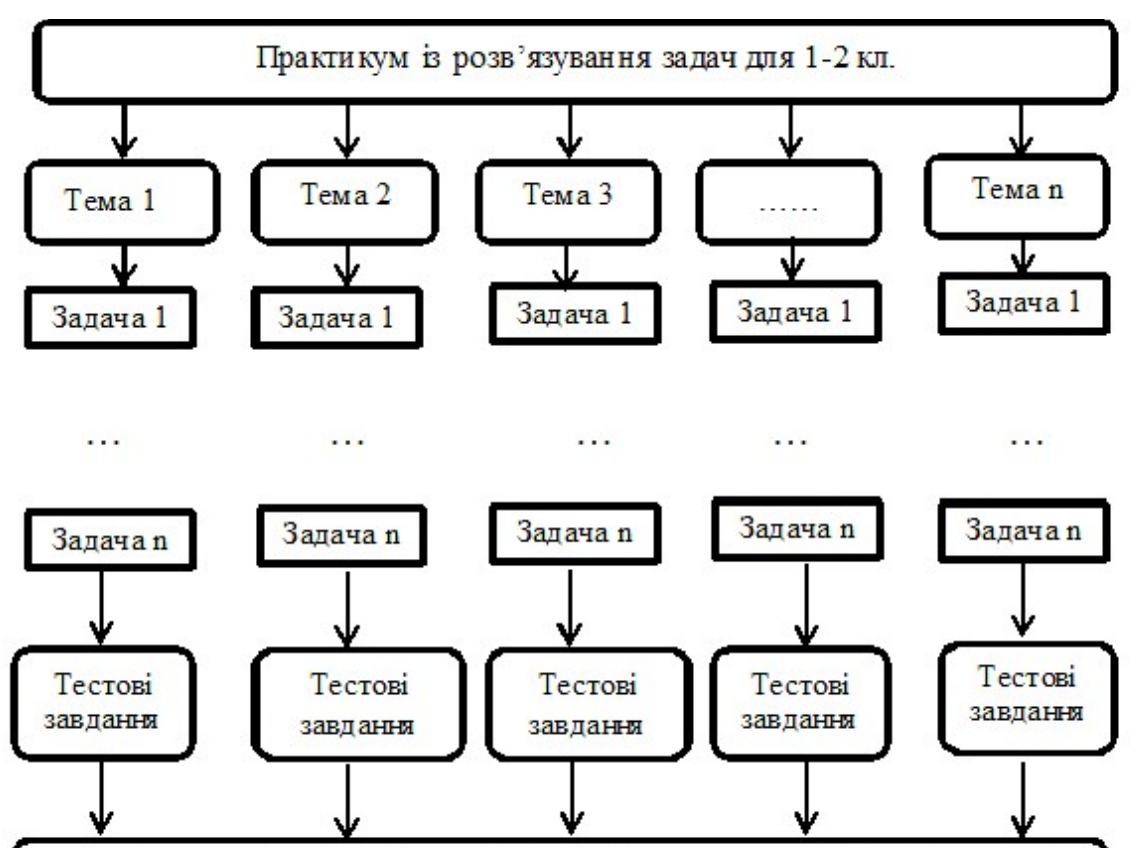

Від еом ат еріали з гриклад ами розв'я занни задач, вікт орини, кросворди, творчі завдання

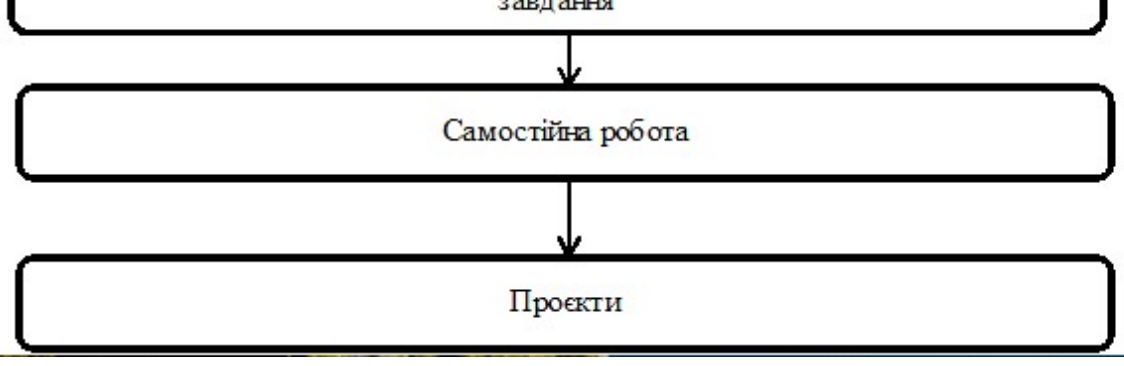

Рис 1. Фрагмент моделі навчальної системи зі шкільного курсу Інформатики

інформації (візуалізацію). Одні і ті самі дані можуть представлятися різними способами і в різних форматах. Наприклад, колекцію об'єктів за допомогою різних уявлень можна уявити на рівні користувача інтерфейсу як у табличному вигляді, так і за списком; на рівні API можна експортувати дані як в JSON, так в XML або XSLX.

3. Контролер / Controller - забезпечує зв'язок між користувачем і системою, використовує модель і уявлення для реалізації необхідної реакції на дії користувача.

Більшість фреймворків для розробки вебдодатків побудовані на парадигмі MVC, тому досить просто зрозуміти принцип роботи будьякого нового фреймворка. За допомогою фреймворків здійснюється пошуку шляхів та виклик відповідного методу. Отже, після введення певного шляху в URL, відбувається виклик певного методу із параметрами. Значення цих параметрів ми визначаємо самостійно. Якщо допустимі значення параметра задовольняють систему, вони будуть зберігатися і передаватись на виконання.

Дані в системі зберігаються у вигляді ключа за допомогою системи кешування, яка дає змогу здійснювати пошук даних за відомим ключем. Дані зберігаються в оперативній пам'яті і завдяки цьому досягається швидкість їх пошуку. Але при перезавантаженні серверу, всі дані з оперативної пам'яті видаляються, тому доцільно розміщувати цю систему на окремому сервері. Далі слід здійснити налаштування його для веб-додатку. Бачимо, що найбільше в кешуванні даних потребує таблиця $з$ даними про користувачів. Логічно, що кешувати будемо дані для таблиці учнів.

Щоб уникнути помилок програми, ми використовували unit тестування. При виборі певного методу класу тепер ми знаємо, які повинні бути вхідні та вихідні дані. Потім unit тест потрібно запустити на виконання і отримаємо результат, який покаже чи збігається очікуваний результат $з$ дійсним. 
Для налаштування серверів використаємо Amazon EC2, який має наперед підготовлені типи серверів. Вони мають певну кількість оперативної пам’яті, різні типи процесорів, величину оперативної та звичайної пам'яті, інші параметри. Це і дозволяє створити потрібний веб-сервер, для якого потрібно налаштувати групу безпеки. Було обрано програмне забезпечення з використанням OC CentOS. Тип сервера можна вибрати серед типів Amazon EC2. Створена нова група безпеки не буде дозволяти підключатись 3 невідомих IPадрес. Через протокол передачі даних HTTPS можна отримати доступ до сервера. Щоб забезпечити масштабування серверів, зі створеного сервера зроблено копію. Ї̈ї було додано в групу масштабування та систему, які здійснює балансування навантаження. Виставлено правило, що при зростанні навантаження на сервер більш ніж на 75\%, виконується автоматичне підняття ще одного сервера для розподілу навантаження.

Висновки. Серед різноманітності інформаційнокомінікаційних технологій, випускники закладів вищої освіти повинні самостійно досліджувати й вивчати необхідність і можливості їх застосування у своїй професійній діяльності. Зокрема, створювати власні веб-орієнтовані навчальні системи. Інтеграція веб-технологій створення навчальних систем, методів професійного навчання майбутніх учителів інформатики дозволить більш якісно їх підготувати до майбутньої фахової діяльності.

Перспективу подальших досліджень вбачаємо у розширенні функційності веб-орієнтованої навчальної системи та співпраці із більш масштабними освітніми навчальними програмами.

\section{ЛIТЕРАТУРА}

1. Овчаров С. Актуальні проблеми професійної підготовки учителів інформатики. Педагогічні науки. Збірник наукових праџь. Полтава, 2011. C. $73-78$.

2. Никонс Р. Создаем динамические веб-сайти с помощью PHP, MySQL, JavaScript, CSS и HTML5. 3-е изд. Санкт-Петербург, 2015. 688 с.

3. Мова розмітки HTML. URL: https:// uk.wikipedia.org/wiki/HTML.

4. Мова стилів CSS. URL: https://uk.wikipedia.org/ wiki/CSS
5. Мова програмування Javascript. URL: https:/ /uk.wikipedia.org/wiki/JavaScript

6. Документація Bootstrap. URL: http:// getbootstrap.com/

7. Мова програмування PHP. URL: https:// uk.wikipedia.org/wiki/PHP

8. Офіційна документація по фреймворку Laravel. URL: https://laravel.com/

9. Опис технологіï RESTfull. URL: https:// uk.wikipedia.org/wiki/REST.

10. Стандарти мови програмування РНР щодо написання коду. URL: http://www.php-fig.org/psr/

\section{REFERENCES}

1. Ovcharov, S. (2011). Aktualni problemu profesiynoi pidgotovku uchuteliv informatuku [Actual problems of professional training of computer science teachers]. Pedagogical sciences. Collection of scientific works. Poltava, pp. 73 - 78. [in Ukrainian].

2. Nikons, R. (2015). Sozdaem dinamicheskie vebsaytu s pomoshchyu PHP, MySQL, JavaScript, CSS i HTML5 [Building dynamic websites with PHP, MySQL, JavaScript, CSS и HTML5]. 3rd ed. St.Petersburg, 688 p. [in Russian].

3. Mova rozmitki HTML [HTML markup language ]. Available at: https://uk.wikipedia.org/wiki/ HTML. [in Ukrainian].

4. Mova stiliv CSS [CSS style language]. Available at: https://uk.wikipedia.org/wiki/CSS [in Ukrainian].

5. Mova programuvannya Javascript [Javascript programming language]. Available at: https:// uk.wikipedia.org/wiki/JavaScript [in Ukrainian].

6. Dokumentatsiya Bootstrap [Bootstrap documentation]. Availableat: http://getbootstrap.com/[in Ukrainian].

7. Mova programuvannya PHP [PHP programming language]. Available at: https://uk.wikipedia.org/wiki/ PHP [in Ukrainian].

8. Ofitsiyna dokumentatsiya po freymvorky Laravel [Official documentation for the Laravel framework]. Available at: https://laravel.com/ [in Ukrainian].

9. Opus tekhnologii RESTfull [Description of RESTfull technology]. Available at: https:// uk.wikipedia.org/wiki/REST [in Ukrainian].

10. Standartu movu programuvannya PHP shchodo napusannya kody [PHP programming language standards for writing code]. Available at: http://www.php-fig.org/psr/

Стаття надійшла до редакції 16.08.2021

\section{CS808OC2G5808OCRCS80

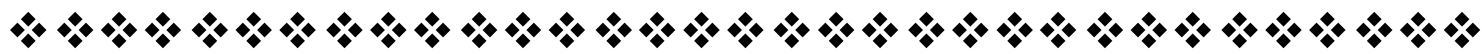

